\title{
Impact of environmental and social attitudes, and family concerns on willingness to pay for improved air quality: a contingent valuation application in Mexico City
}

\author{
Massimo Filippini' ${ }^{1,2}$ • Adán L. Martínez-Cruz ${ }^{2}$
}

Received: 1 May 2015/Revised: 24 October 2016/ Accepted: 1 November 2016/

Published online: 11 November 2016

(C) The Author(s) 2016. This article is published with open access at Springerlink.com

\begin{abstract}
By means of a single-bounded, referendum format contingent valuation, this paper estimates willingness to pay (WTP) for improved air quality among residents of Mexico City Metropolitan Area (MCMA). Findings from this paper illustrate heterogeneity in WTP associated with environmental and social attitudes, and family concerns. For instance, WTP is higher than average if respondents state a very high priority to air pollution but smaller than average if respondent's household contains more adults than the sample median. This contingent valuation exercise provides elements to carry out cost-benefit analysis of environmental policies both recently implemented and currently under discussion in the MCMA context. For instance, a cost-benefit analysis using estimates from this paper suggests benefits from improved air quality surpass the costs of investing in hybrid buses. Usefulness of this study is underscored by pointing out recent evidence suggesting that (1) air pollution in MCMA has larger health impacts than in similar cities located in developed countries, and (2) policies tackling air pollution in MCMA have had no impact on pollution levels.
\end{abstract}

Keywords Air quality - Willingness to pay · Mexico City · Contingent valuation · Attitudes

JEL Classification Q51 - Q53 - D61

Adán L. Martínez-Cruz

madan@ethz.ch

1 USI, Lugano, Switzerland

2 CEPE, ETH Zurich, Zürichbergstrasse 18, 8032 Zurich, Switzerland 


\section{Introduction}

Air pollution remains a pressing issue in megacities located in developing countries. Mexico City Metropolitan Area (MCMA) is an infamous case. Pollution levels in MCMA regularly surpass limits suggested by the World Health Organization (CAI 2013). Also, MCMA has been ranked as the second most congested city in the world during 2014. ${ }^{1}$ Effects of air pollution on the respiratory system have long been documented in MCMA (e.g. Escamilla-Nuñez et al. 2008; Romieu et al. 2008). Recent epidemiological studies report neuro-inflammation in otherwise healthy children residing in MCMA (Calderón-Garcidueñas et al. 2008). In general, air pollution produces larger health impacts in Mexico city than in similar cities located in a developed country (Arceo-Gomez et al. 2012).

Public policies aiming to reduce air pollution have proved unsuccessful in MCMA. Launched in 1989, Hoy No Circula (HNC) program represents the most important governmental effort aiming to reduce pollution levels in MCMA. ${ }^{2}$ HNC limits the number of weekdays a car is driven in Mexico City. HNC tackles the use of cars because it is the largest contributor to air pollution in MCMA-45\% of volatile organic compounds and $81 \%$ of total nitrogen oxides (Molina and Molina 2002). Empirical studies have reported no impact from $\mathrm{HNC}$ on air pollution levels and an undesirable positive impact on numbers of cars driven (Gallego et al. 2013a, b; Davis 2008). Authorities frequently implement a pre-contingency plan that imposes temporary driving restrictions. ${ }^{3}$ The most recent attempt to improve air quality, consisting in extending HNC to Saturdays, has been launched in July 2014.

A question arises in this context-what is the WTP of a resident of MCMA for improved air quality? This paper elicits WTP for improved air quality by means of a single-bounded, referendum format contingent valuation question. Respondents state their willingness to monetarily contribute to improve air levels from observed regular quality to good quality. This paper pays particular attention to differences in WTP explained by individualś attitudes and concerns in three realms-environmental, social, and family. The economic literature has already established the relevance of individuals attitudes and concerns as factors behind variability in WTP (e.g. Bartczak 2015; Martínez-Espiñeira and Lyssenko 2011; Spash 2006; Spash et al. 2009). This paper illustrates this relevance in the Mexican context. To measure attitudes, respondents are asked to state their opinion on how important is the air pollution problem and the poverty/economic development problem. To measure concerns, respondents are asked to report (1) whether a family member (including himself) suffers an allergy or a respiratory illness; (2) whether there is a car at the household; and (3) family size.

Average WTP in this paper-US \$262 (2008 US dollars) - falls close to comparable estimates reported in previous studies. For instance, Hanna and Oliva (2015) report US

\footnotetext{
1 See Tom Tom Traffic Index 2015, available at http://www.tomtom.com/en_gb/trafficindex/\#/.

2 For a detailed description of additional policies aiming to reduce air pollution in MCMA, see GarcíaRobles (2010), and McKinley et al. (2005).

3 e.g. http://mexico.cnn.com/salud/2013/05/22/contingencia-ambiental-que-es-y-que-hacer-cuando-sedeclara, http://www.milenio.com/df/contaminacion_DF-precontingencia_ambiental_DF-contaminacion_ ozono_DF_0_475152757.html.
} 
\$247 when using a gain-in-productivity approach. Results illustrate heterogeneity in WTP associated with environmental and social attitudes, and family concerns. For instance, while respondents posing a very high priority to the air pollution problem have higher than average WTP (US \$302), respondents in a household with more adults than the sample median (i.e. 2) have a lower than average WTP (US \$214). While respondents posing a very high priority to the poverty/economic development problem have smaller than average WTP (US \$222), respondents with a family member suffering allergies or respiratory illness have higher than average WTP (US \$295). Indeed, this contingent valuation exercise provides elements to carry out cost-benefit analysis of policies aiming to improve air quality in MCMA-e.g. expansion of metro system, maintenance or replacement of sources of liquid petroleum gas leaks, taxi renovation, and use of hybrid buses (see García-Robles 2010; McKinley et al. 2005). Instances of cost-benefit analysis based on these estimates are presented in the discussion section.

\section{Valuation methodology}

Data are gathered through a contingent evaluation elicitation. Contingent evaluation elicitations have widely been used in countries facing air quality problems-e.g. Taiwan (Alberini et al. 1997), China (Wang and Zhang 2009), and Sweden (Carlsson and Johansson-Stenman 2000). A single-bounded, referendum format elicitation has been implemented in this study. This type of elicitation describes a hypothetical market as a referendum in which respondents are asked whether they would vote for or against a project in a public vote (Kling et al. 2012). Advantages of this type of question include theoretical incentive compatibility, conceptual simplicity, and similarity to a real-life decision mechanism. Single-bounded questions, however, do not yield the most statistically efficient WTP estimates. Increase in statistical efficiency is obtained through double-bounded (Hanemann et al. 1991) and one-and-one-half-bounded (Cooper et al. 2002) approaches. These alternatives share several inconveniences with the single-bounded approach-warm glow effect, anchoring, sensitivity to scope, and hypothetical bias (Carson 2012; Carson et al. 2001; Bateman et al. 2009). In addition, one-and-half-bounded approach may be non-incentive compatible (Bateman et al. 2009).

Both conceptual simplicity and similarity to a real-life decision mechanism have driven the selection of single-bounded approach in this study. Both features facilitate administration and execution, particularly in developing countries where contingent valuation applications are still uncommon. ${ }^{4}$ Administration and

\footnotetext{
${ }^{4}$ While Mexico is an OECD member, this paper follows recommendations targeting developing countries because contingent valuation studies in Mexico are still rare. A non-exhaustive search yielded 15 published studies in which Mexican respondents stated WTP through a contingent valuation question or a discrete choice experiment. Papers focused on water-related issues include Almendarez-Hernández et al. (2013), Avilés-Polanco et al. (2010); Pérez-Verdin et al. (2011); Rivera-Planter and Muñoz-Piña (2005), SánchezBrito et al. (2013), Soto-Montes de Oca et al. (2006), and Vásquez et al. (2009). A few studies have researched preferences of farmers with respect to natural resources (Birol et al. 2009; Scarpa et al. 2003). Additional topics cover valuation of food safety (Tonsor et al. 2009), smoking cessation treatment (HerediaPi et al. 2012), cross-border health insurance (Vargas-Bustamante et al. 2008), environmentally certified products (Husted et al., 2014), and archeological zones (Beltrán and Rojas 1996).
} 
execution are hampered if enumerators have poor understanding of the contingent valuation instrument (Whittington 2002). Conceptual simplicity and comparability to a real-life situation eases explanation and understanding for both enumerators and respondents. A single-bounded approach is also less time-consuming which increases the response rate.

The elicitation protocol used in this paper first elicits respondents' attitudes. Respondents were asked to rank how important are air pollution and poverty/ economic development problems to Mexico. Respondents separately ranked the level of importance by choosing one of four categories-very important, important, slightly important, and not important at all.

Then a summary of air pollution effects on human health is presented. Respondents are explained how air pollution is measured in Mexico and informed about air pollution levels in Mexico City during a normal year.

Then a strategy to improve air quality is described. This strategy would introduce filters to the exhaust systems of cars and industry. In addition, a limit would be imposed to the sulfur in fossil fuels of residential and industrial use. This strategy would bring pollutants' concentrations down from observed regular quality levels to good quality levels. This change in air quality would save around 2200 lives and avoid 37,000 hospital admissions yearly.

The protocol explains the government is considering putting this plan to a vote. Respondents are informed that they would partially cover costs of implementing this policy. The phrasing of the elicitation question is as follows: taking into consideration that the strategy described above will increase your annual expenses by __, would you be willing to support this strategy if the government put it to a vote?

Socioeconomic characteristics and family concerns are gathered in the last section of the protocol. Respondents report whether someone in his/her family (including his/herself) suffers from allergies or a respiratory illness. Respondents also report whether a car is owned by someone in the family. Owning a car is considered a family concern because, in order to comply with HNC requirements, owners must face annual expenses and transactional costs-sometimes involving a bribe to personnel in charge of car's inspections (Oliva, 2012). The number of household members is also a family concern. The respondent is asked for the number of adults and children at home.

\section{Data}

\subsection{Collection}

Data were gathered from mid-December 2007 to mid-January 2008. A random sample of 1812 individuals was approached in public places-e.g. malls, parks, and small businesses - located in Delegación Gustavo A. Madero (DGAM), a county in Mexico City. Two features make DGAM an insightful case for the purposes of this study: air pollution levels and relative economic development. That is, DGAM represents a case in which air pollution is a local environmental issue impacting 
people whose average income is enough to expect positive WTP for air quality but where unequal economic development is expected to yield a trade-off between environmental and social attitudes, and family concerns.

DGAM consistently ranks among the most polluted counties of MCMA since early 1990s (SMAGDF 2009; Proaire 2001;). This feature makes air pollution a local environmental issue for inhabitants of DGAM. Although Mexico city as a whole struggles with air pollution, pollution levels in the south of Mexico City are regularly lower, making air pollution a relatively less local issue in cleaner areas. Arguably, non-market valuation of an issue that directly concerns respondents is less likely subject to the possibility that respondents behave as citizens (Nyborg 2000). When behaving as citizens, respondents may reveal social preferences instead of personal preferences due to a "warm glow" effect (Kling et al. 2012). This study seeks personal preferences because interest is on individuals' trade-offs.

No-responses to contingent valuation questions are partially driven by budget constraints. Thus, a useful case study must refer to a population that can potentially afford an improvement in air quality. While a few other counties in Mexico City face at least as much air pollution as DGAM, income in these counties tends to be smaller than in DGAM. Per capita GDP in DGAM during 2009 was around 12,900 US dollars of 2005, just 100 US dollars below the median in Mexico City (CEFP 2009). A trade-off between attitudes and concerns is more likely present in a context where economic development has spread unequally. Since early 1990s, DGAM's Gini Index has been around 0.38 , and $7 \%$ of people have been living under food poverty conditions (CEFP 2009).

\subsection{Descriptive statistics}

Once missing values have been excluded, 1541 observations are used in statistical analysis. Descriptive statistics refer to these observations. Table 1 presents a consistency test by checking whether percentage of no-responses increases as bid increases. Bids presented to respondents take a value between US \$7.5 and US $\$ 87.5$ (2008 US dollars). Although not monotonically, percentage of no-responses increases from $10.5 \%$ when bid is US $\$ 7.5$ to $31.6 \%$ when bid is US $\$ 87.5$.

Table 2 compares averages of socioeconomic characteristics in the sample against DGAM values. Sample values for percentage of males, average age, number of household members, proportion of retired people, and car at household are not statistically different (at 95\% confidence) from DGAM values-0.48, 38.50, 3.70, 0.12 , and 0.76 , respectively. Proportion of unemployed people is larger in the

Table 1 Percentage of no-responses by bid

\begin{tabular}{llllllllll}
\hline \multicolumn{1}{c}{ Bids in 2008 US dollars } \\
\cline { 2 - 9 } & 7.5 & 12.5 & 25 & 37.5 & 50 & 57.5 & 62.5 & 75 & 87.5 \\
\hline Respondents & 180 & 165 & 145 & 146 & 192 & 175 & 188 & 179 & 171 \\
\%no-responses & 10.5 & 4.9 & 0.0 & 15.0 & 15.7 & 20.0 & 17.6 & 23.5 & 31.6 \\
\hline
\end{tabular}

\footnotetext{
${ }^{a}$ Bids are randomly assigned to respondents
} 
Table 2 Socioeconomic characteristics in sample and populations $(n=1541)$

a Sources: CEFP (2009), INEGI (2010), INEGI (2016)

\begin{tabular}{lrcll}
\hline & $\begin{array}{l}\text { Mean } \\
\text { (A) }\end{array}$ & Std. Dev & $\begin{array}{l}\text { DGAM }^{\mathrm{a}} \\
(\mathrm{B})\end{array}$ & $\begin{array}{l}t \text { test } \\
(\mathrm{B}-\mathrm{A})\end{array}$ \\
\hline Male & 0.48 & 0.49 & 0.48 & 0.00 \\
Age & 39.01 & 14.44 & 38.50 & 1.38 \\
Household members & 3.77 & 1.59 & 3.70 & 1.72 \\
Unemployed & 0.66 & 0.78 & 0.54 & 6.03 \\
Retired & 0.12 & 0.32 & 0.12 & 0.00 \\
Car at household & 0.74 & 0.44 & 0.76 & 1.78 \\
Sick household member & 0.33 & 0.47 & - & - \\
\hline
\end{tabular}

Table 3 Respondents' attitudes about air pollution and poverty/economic development $(n=1541)$

\begin{tabular}{llr}
\hline Economic & Air pollution & \\
\cline { 2 - 3 } development & Not very important & Very important \\
\hline Not very important & $17.72 \%$ & $3.89 \%$ \\
Very important & $20.51 \%$ & $57.88 \%$ \\
\hline
\end{tabular}

Table 4 Monthly household income by range and respondent's contribution $(n=1541)$

\begin{tabular}{llcc}
\hline Monthly household & \multicolumn{2}{l}{ Respondent's contribution to household income } \\
\cline { 2 - 4 } income & Less than 50\% & $50 \%$ to $75 \%$ & more than $75 \%$ \\
\hline Less than US \$567 & 18.36 & 11.10 & 12.07 \\
Between US \$567 and US \$ 967 & 16.22 & 5.71 & 11.49 \\
Between US \$967 and US \$2167 & 7.14 & 6.75 & 7.85 \\
Between US \$2167 and US \$5000 & 0.00 & 3.31 & 0.00 \\
\hline
\end{tabular}

sample -0.66 versus 0.54 . The proportion of households with at least one member affected by a respiratory illness or allergy is not readily available at the county level. Our own estimations, based on respiratory-related morbidity and/or mortality, do not yield convincing figures and, therefore, we do not present them in Table 2.

Table 3 reports respondents' opinions about air pollution and poverty/economic development. Three categories-important, slightly important, and not important at all-are grouped in one category labeled "not very important". Both issues are considered very important by $57.88 \%$ of respondents; $20.51 \%$ consider poverty/ economic development a very important and air pollution a not very important issue; $3.89 \%$ consider the opposite; and $17.72 \%$ consider none of the issues very important.

Table 4 reports stated range in which monthly household income falls and respondent's contribution to this monthly income. Considering the tendency to miss-report income, categorization of income provides ordinal information. That is, categories can be seen as reflecting order but not magnitude. Tabulation and posterior inclusion in statistical analysis of household income and respondent's 
contribution to income is intended to control for budgetary restrictions. Notice the small percentage of respondents from households with the highest income category $(3.31 \%)$ and the lack of respondents in this category that contribute either less than $50 \%$ or more than $75 \%$.

\section{Results}

Results from logit specifications on WTP responses are reported in Table 5. The first column reports the analysis on the entire sample, i.e. 1541 observations. The rest of the specifications reported in Table 5 work as robustness checks. We check that results are robust to the exclusion of the richest and the oldest respondents (columns two to four in Table 5) and to the presence of protest respondents (fifth column in Table 5).

Coefficients in Table 5 are not interpretable as marginal effects but we discuss their sign which points to the direction of the effect of the corresponding variable. Focusing on the results arising from the analysis of the entire sample (first column), the first set of coefficients in Table 5 refers to the key variables in this study-i.e. bid, environmental and social attitudes, and family concerns. Bid's negative coefficient implies that a higher proportion of no is observed as the bid increaseswhich is consistent with the exploratory analysis in Table 1 . When focusing on the environmental and social attitudes, we notice that while respondents that consider air pollution a very important problem have larger WTP (which we learn from the positive sign of 1.15), respondents that consider poverty/economic development a very important problem have smaller WTP (which is inferred from its corresponding -1.31 coefficient). Importantly, the impact on WTP remains positive when respondent considers both problems are very important (which is implied by the 1.39 estimate).

The other set of key variables in our study refer to three family concernswhether a family member is sick of a respiratory illness or allergy, whether there is a car at the household, and family size. Family size is included through two variables-whether adults at the household are more than sample median (i.e. 2), and whether children at household are more than sample median (i.e. 1). According to the second set of coefficients in Table 5, having a sick member increases WTP for improved air quality. Having a car at the household does not impact the WTP. A respondent whose household is composed by more adults than the median has smaller WTP. Number of children at home has no impact on WTP.

The rest of the coefficients have the expected sign or have no impact at all-e.g. gender of respondent does not impact WTP, a respondent with a full-time job reports higher WTP than a respondent with no job, older respondents tend to report higher WTP, and richer respondents tend to report higher WTP with exception of the richest respondents. Several possibilities are behind the negative sign associated with the richest respondents. A first explanation is that richer people may already be taking precautions against air pollution and, therefore, be less willing to contribute to a public good. For instance, if richer respondents have already bought indoor air purifiers and/or own houses with large gardens, they may be less willing to pay for a 


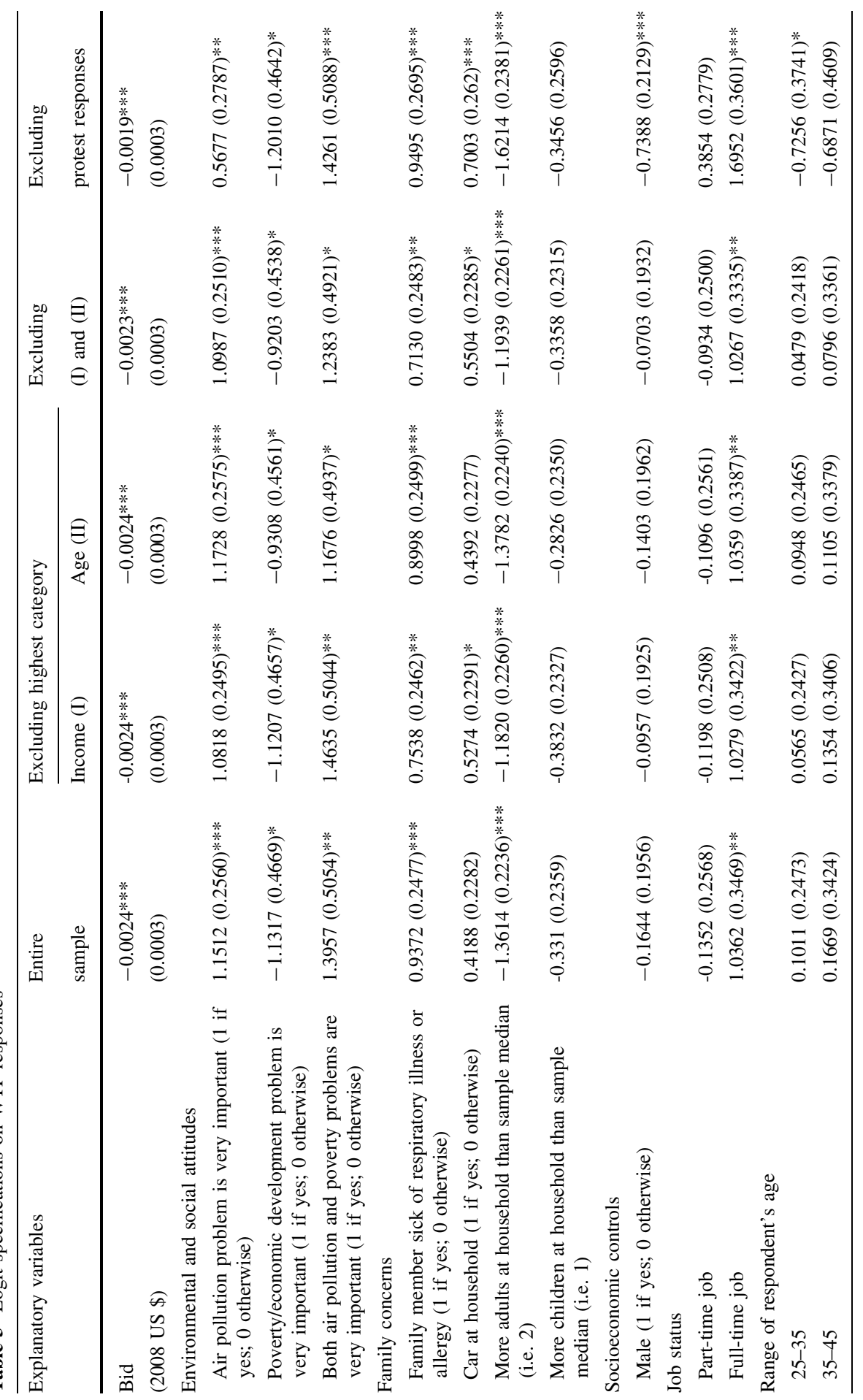




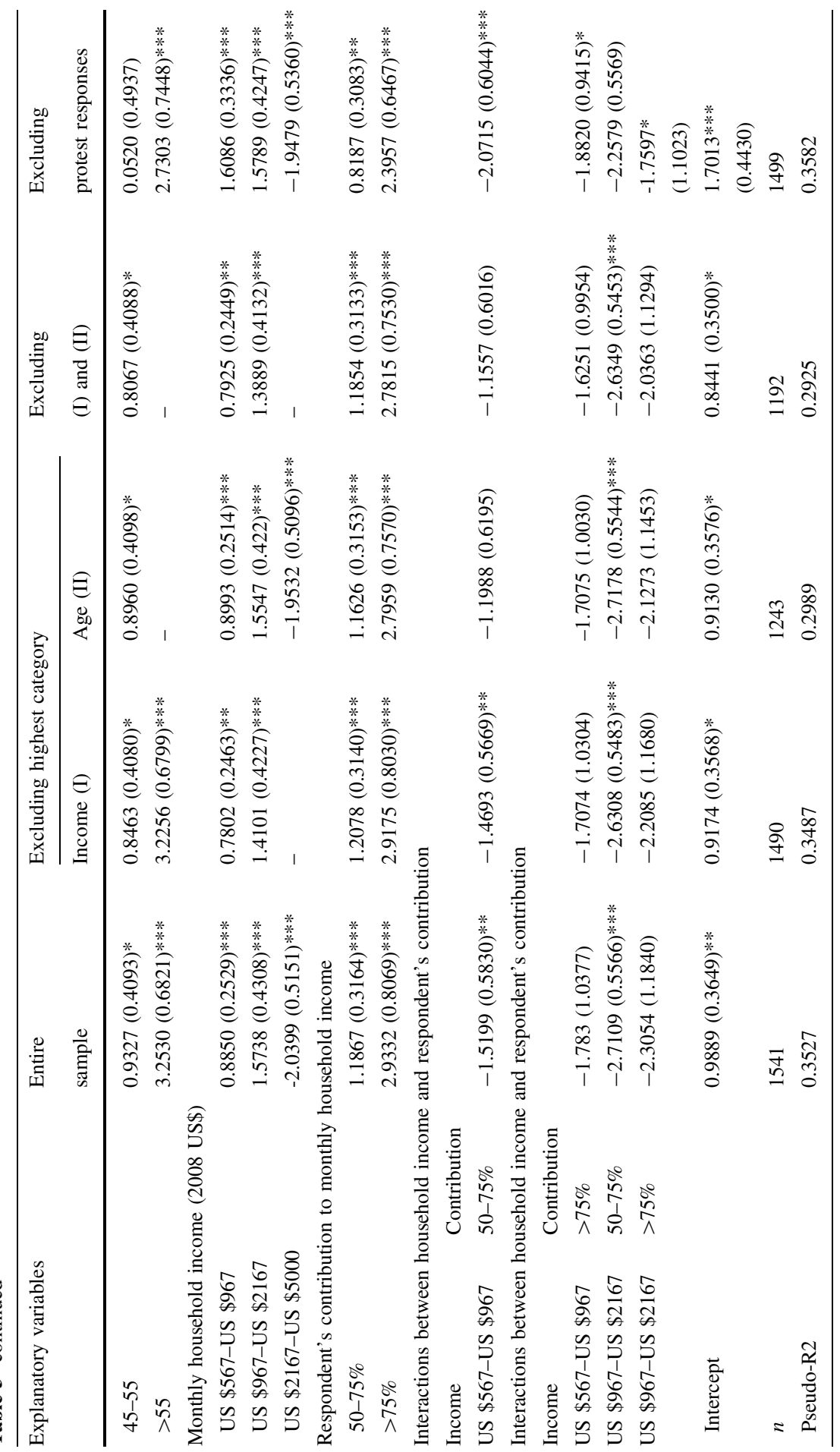




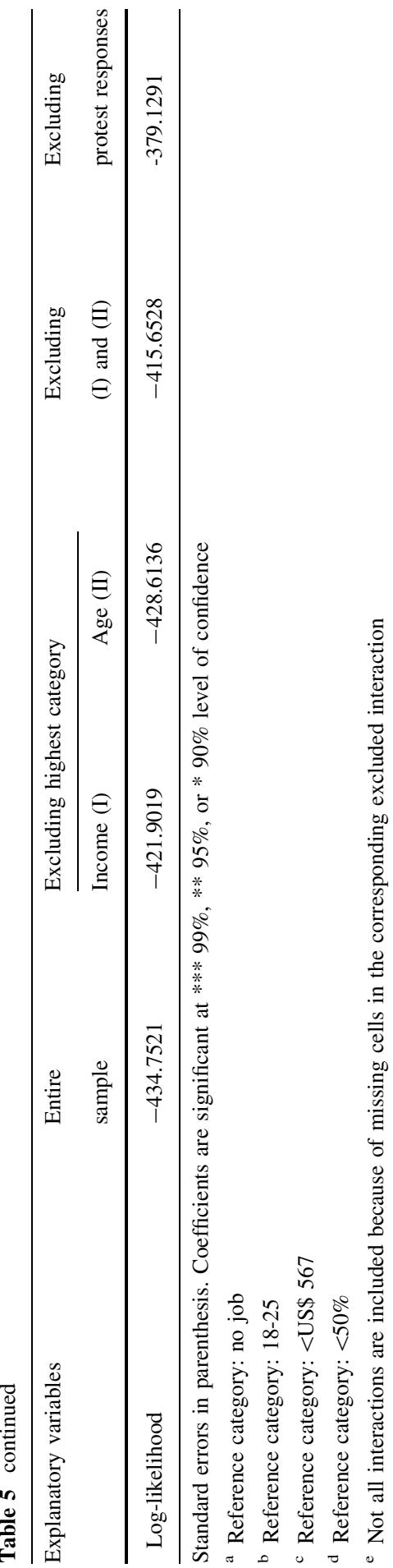


cleaner air. This explanation, of course, does not exclude the possibility that richer respondents may be intrinsically more selfish.

A couple of variables have been included to test whether respondents have taken into account their income when answering the WTP questions. Controlling for income category allows differences in marginal utility of income across income levels (Haab and McConnell 2002). While household income may reflect a household's budget restriction, a respondent may not be the household decision maker. A strategy to capture a respondent budgetary constraint is interacting categories of monthly household income with categories of respondent's contribution to household income. Respondent's contribution categories yield positive coefficients, which implies that a larger contribution to the household income also increases the WTP. However, interaction effects are negative and significant in a couple of cases. This implies that increase in WTP is not monotonic with income and contribution.

We do carry out three robustness checks to the presence of the richest and oldest respondents. The robustness check to age is motivated by relatively large coefficient associated with the category of people older than 55-while variation in age barely matters for categories below 55, the coefficient for people older than 55 is 3.25 . The robustness check for income is motivated by the negative sign of the coefficient corresponding to the richest respondents $(-2.039)$. This sign stands out because the signs of the coefficients associated for lower income categories are positive and significant. While a negative sign is feasible even if air quality is a normal good, ${ }^{5}$ we explore whether the exclusion of such respondents change the main message of the initial specification.

Results reported in columns two to four refer to specifications that work as robustness checks to age and income. The second column reports results from a specification that excludes the observations in the highest income category-51 observations. The third column refers to a specification excluding respondents older than 55-298 observations. The fourth column reports results from a specification excluding observations in the highest income and age categories. These three specifications deliver results that are qualitatively similar to those obtained by analyzing the entire sample-i.e. signs remain identical and magnitudes of the coefficients are similar when excluding the richest, the oldest or both. Thus, we conclude that results are not driven by inclusion or exclusion of age and income categories.

An additional robustness check is carried out with respect to the presence of protest respondents. Protest response is an empirical staple of the contingent valuation literature (see Strazzera et al. 2003; Chen and Hua 2015). The term refers to the respondents that report zero WTP due to non-budget related reasons. That is, a respondent stating that his/her budget is not enough to pay for cleaner air quality is

\footnotetext{
5 For instance, in the literature valuing the presence of urban and peri-urban trees and forests, some studies have reported a positive income elasticity, other studies have yielded no significant effect from income, with a few studies even reporting negative income elasticities (see Brander and Koetse 2011). A negative income elasticity is a reasonable result because, in our context, it is possible that beyond certain income level people may prefer to purchase cleaner air in a private market in the form of large gardens at home, or via indoor air purifiers.
} 
consistent with utility maximization theory. But we may not say the same about respondents that express distrust or complaint about the WTP survey in itself. In this study, protest respondents believe that they should not pay because (1) clean air is a right; (2) the scenario is not believable or practical; (3) the program should be financed by the polluters; and (4) the government administrators are not able to solve the problem of air pollution.

We check whether results are driven by the presence of protest respondents. The fifth specification in Table 5 reports results from analyzing a sample that excludes protest respondents. In general, results are qualitatively similar to those obtained when analyzing the entire sample. The coefficient that deserves the most attention is the one capturing the impacts from the bid. Significant differences in the estimation of the bid coefficient directly impact the point estimates of the WTP because $E(\mathrm{WTP})=X \widehat{\beta} /-\widehat{\gamma}$, where $X$ includes a vector of ones and the explanatory variables of the empirical specifications, and $\hat{\beta}$ is the vector of corresponding estimated coefficients and $\hat{\gamma}$ is the estimated coefficient for bid. ${ }^{6}$ In this study, the point estimate of the bid coefficient on the entire sample is -0.0024 ; and the bid coefficient on the sample excluding protest respondents is -0.0019 . These point estimates, however, are not statistically different-the $95 \%$ confidence interval from the trimmed sample $(-0.0025$ to -0.0013$)$ includes the -0.0024 obtained on the entire sample. Putting together the fact that results do not differ qualitatively and that the bid coefficient is not statistically different when excluding protest respondents, we conclude that results are robust to the presence of protest respondents.

Results, in WTP terms, from analyzing the entire sample are graphically illustrated in Fig. 1. This figure depicts WTP for improved air quality for different respondents' profiles. Environmental and social attitudes, and family concerns are varied with respect to a baseline profile. This profile corresponds to a respondent with a full-time job, between 45 and 55 years of age, with household income between US $\$ 967$ and US $\$ 2167$ to which he/she contributes more than $75 \%$. This respondent has an average WTP of US \$262. The dashed line in the middle in Fig. 1 shows the variation in WTP when environmental and social attitudes are taken into account. If respondent considers air pollution a very important problem, WTP increases to US \$302. In contrast, WTP decreases to US \$222 if respondent considers that poverty/economic development is a very important problem. WTP is US \$ 311 if respondent considers both problems very important.

Respondents have higher WTP if a family member suffers a respiratory illness or allergy. This holds regardless of environmental and social attitudes. As illustrated by the straight line in Fig. 1, WTP increases by around $12 \%$ when a family member is sick. It is still the case that, among respondents with a sick family member, the respondent considering poverty a very important problem is the one with the lowest WTP (US \$255). This respondent has lower WTP than respondents considering poverty is not a very important problem and with no sick family member-US $\$ 262$, US \$302, and US \$311, as illustrated by the line in the middle in Fig. 1. This

\footnotetext{
${ }^{6}$ For details, see Haab and McConnell (2002).
} 


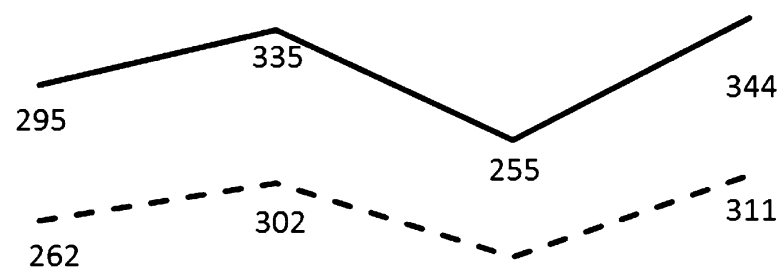

222

214 254

Neither

Air pollution Poverty

Both

Family member is sick

- Baseline

More adults than sample median

Fig. 1 WTP (2008 US\$) for improved air quality by environmental and social attitudes, and family concerns. Baseline refers to a respondent with a full-time job, between 45 and 55 years of age, with household income between US \$967 and US \$2167 to which he/she contributes more than $75 \%$

last result implies that considering poverty/economic development a very important has a stronger negative impact in WTP than having a sick family member.

Respondents have lower WTP if they are living in a household with more adults than the sample median. This holds regardless of environmental and social attitudes. As illustrated by dashed line at the bottom of Fig. 1, WTP decreases by around 22\% when there are more adults in the household than the sample median.

WTP illustrated in Fig. 1 and their corresponding 90\% empirical confidence intervals are reported in Table 6. Confidence intervals are obtained from 10,000 Krinsky-Robb repetitions (Krinsky and Robb 1986). Conventional statistical comparison of means is not appropriate in this context because average WTP and their corresponding distributions are correlated. In this context, non-parametric, multivariate comparisons of distributions are the correct tool (see Poe et al. 1994, 1997). These comparison are, however, non-essential to extract lessons from our results: environmental and social attitudes, and family concerns induce tradeoffs in WTP.

\section{Conclusions and discussion}

Estimated annual average WTP to improve air quality in MCMA is US \$ 262 (2008 US dollars). Taking into consideration the $90 \%$ confidence interval (US \$194-US \$336), this value is not statistically different from comparable average values reported in previous studies. Hanna and Oliva (2015) estimate gains in labor productivity of US $\$ 247$ per worker annually if a policy is implemented to reach pollution levels with similar impacts than those described in the contingent valuations scenario in this paper. 
Table 6 WTP estimates (2008 US dollars) and 90\% empirical confidence intervals ${ }^{\mathrm{a}}$

\begin{tabular}{llll}
\hline & Mean & \multicolumn{2}{l}{$90 \%$ confidence interval } \\
\cline { 3 - 4 } & & Lower bound & Upper bound \\
\hline Neither problem is very important (N) & 261.65 & 193.77 & 335.86 \\
Air pollution is very important (A) & 301.98 & 230.97 & 379.93 \\
Poverty/economic development is very important (P) & 221.68 & 163.75 & 284.76 \\
Both problems are very important (BP) & 311.28 & 242.07 & 388.38 \\
Family member suffers respiratory illness or allergy (I) & 294.76 & 219.53 & 377.60 \\
(I) + (A) & 335.08 & 256.78 & 422.13 \\
(I) + (P) & 254.79 & 191.04 & 325.91 \\
(I) + (BP) & 344.38 & 267.72 & 430.15 \\
More adults than sample median (M) & 213.69 & 150.48 & 282.62 \\
(M) + (A) & 254.01 & 188.29 & 324.62 \\
(M) + (P) & 173.73 & 119.58 & 231.33 \\
(M) + (BP) & 263.32 & 199.03 & 333.89 \\
\hline
\end{tabular}

a 10,000 Krinsky-Robb repetitions

Also, Martínez-Cruz and Sainz-Santamaría (2015) report US \$223 as the average annual WTP of a person to visit a peri-urban natural park near Mexico City (Desierto de los Leones). Arguably, given the peri-urban nature, visits to the Desierto de los Leones Park is at least partially motivated by the need for cleaner air. That is, the WTP of US\$ 223 reported by Martínez-Cruz and Sainz-Santamaría (2015) can be interpreted as an upper bound of the WTP for cleaner air among the population sampled in their study-which is composed by people mostly visiting from the MCMA. Taking into consideration the $90 \%$ confidence interval of the average WTP reported in this study, our estimates are not statistically different from those reported by Martínez-Cruz and Sainz-Santamaría (2015).

Previous studies reporting estimates of WTP to improve air quality in MCMA include those inferring avoided costs of illness (Bell et al. 2006; McKinley et al. 2005; Cesar et al. 2002; Margulis 1996); those inferring values of a statistical life (Hammit and Ibarrarán 2006); and those estimating hedonic price functions (Rodríguez-Sánchez 2014; Gonzalez et al. 2013). Their WTP estimates are, however, not comparable to estimates presented in this paper because the good under valuation is not similar. Specifically, while hedonic prices measure marginal changes in housing prices due to marginal changes in air quality, our contingent valuation exercise refers to a non-marginal change in air quality. For the case of avoided cost of illness, WTP estimates usually refer to aggregate savings from avoided medical expenses given unclear changes in air quality.

In contrast to previous application in the Mexican context, this paper yields WTP estimates differentiated by environmental and social attitudes, and family concerns. Respondents considering air pollution a very important problem have higher WTP than average (US \$302). Respondents considering poverty/economic development a very important problem have smaller WTP than average (US \$222). Respondents with a family member suffering allergies or respiratory illness have higher WTP 
than average (US \$295). Respondents in a household with more adults than the sample median (i.e. 2) have a lower WTP than average (US \$214).

From a public policy perspective, differentiated estimates of WTP are useful in carrying out cost-benefit analysis of environmental policies under different sets of assumptions. For instance, assume authorities only considered citizens with the highest WTP (US \$344). Individuals with the highest WTP have a sick family member, have a full-time job, are between 45 and 55 years of age, and have household income between US \$967 and US \$2167 to which they contribute more than $75 \%$. These individuals represent $1 \%$ of the sample under analysis. Assume this proportion holds for the entire MCMA. Assume 10 million adults in the MCMA. ${ }^{7}$ Thus 100 thousand individuals would be each willing to pay US \$344 annually. Their contributions would amount to US \$34.4 million annually. These resources would be enough to invest in hybrid buses, a project requiring US \$30 million annually according to McKinley et al. (2005).

A limitation in this study is that WTP estimates are based on a sample arguably representative of a county in MCMA. Several assumptions must be made to extrapolate WTP estimates to the entire population in MCMA. Considering that average WTP is in the range reported in previous studies using different approaches and populations, we believe this limitation is relatively minor. Of course, an extrapolation exercise must be careful in using official and most recent numbers available.

Results from this paper can be linked to the literature on micro-foundations of the Environmental Kuznets Curve (EKC). This literature hast yet to provide convincing evidence on whether people trade economic development and environmental quality (see Barbier et al. 2015). A major challenge in this literature is estimation of income elasticity of demand for environmental quality and establishing an unambiguous link between this elasticity and the EKC. This paper gets around estimation of elasticity of demand for environmental quality and instead gathers data reflecting individuals' opinions with respect to economic development and environmental priorities, and uses these opinions in the WTP specifications. With estimates of utility parameters at hand, variations in WTP are inferred for groups of individuals differing in their opinions with respect to economic development and environmental quality. In this way, this paper finds evidence suggesting individuals trade environmental improvements for economic development when stating their WTP for cleaner air.

Acknowledgements Authors acknowledge assistance from Laura González in designing, organizing and implementing the protocol to gather data used in this document. Authors wish to thank an anonymous reviewer whose comments have improved this manuscript. Errors are authors' responsibility.

Open Access This article is distributed under the terms of the Creative Commons Attribution 4.0 International License (http://creativecommons.org/licenses/by/4.0/), which permits unrestricted use, distribution, and reproduction in any medium, provided you give appropriate credit to the original author(s) and the source, provide a link to the Creative Commons license, and indicate if changes were made.

\footnotetext{
7 In 2010, 20 million residents were counted in MCMA, with a little above 10 million being adults (see INEGI 2010).
} 


\section{References}

Alberini A, Cropper M, Fu TT, Krupnick A, Liu JT, Shaw D, Harrington W (1997) Valuing health effects of air pollution in developing countries: the case of Taiwan. J Env Econ Manag 34(2):107-126

Almendarez-Hernández MA, Jaramillo-Mosqueira LA, Avilés-Polanco G, Beltrán-Morales LF, Hernández-Trejo V, Ortega-Rubio A (2013) Valoración económica del agua en un área natural protegida de una economía emergente: recomendaciones para la Reserva de la Biosfera El Vizcaíno, México. Interciencia 38(4):245-253

Arceo-Gomez EO, Hanna R, Oliva P (2012) "Does the effect of pollution on infant mortality differ between developing and developed countries? Evidence from Mexico City," NBER working paper 18349. http://www.nber.org/papers/w18349

Avilés-Polanco G, Huato-Soberanis L, Troyo-Diéguez E, Murillo-Amador B, García-Hernández JL, Beltrán-Morales LF (2010) Valoración económica del servicio hidrológico del acuífero de La Paz, BCS: una valoración contingente del uso de agua municipal. Frontera norte 22(43):103-128

Barbier EB, Czajkowsk M, Hanley N (2015) Is the income elasticity of the willingness to pay for pollution control constant?" Working paper 7/2015(155), University of Warsaw, Faculty of Economic Sciences. http://www.wne.uw.edu.pl/files/5214/2559/0151/WNE_WP155.pdf

Bartczak A (2015) The role of social and environmental attitudes in non-market valuation: an application to the Białowieża Forest. Forest Policy and Economics 50:357-365

Bateman IJ, Day BH, Dupont DD, Georgiou S (2009) Procedural invariance testing of the one-and-onehalf-bound dichotomous choice elicitation method. Rev Econ Stat 91(4):806-820

Bell ML, Davis DL, Gouveia N, Borja-Aburto VH, Cifuentes LA (2006) The avoidable health effects of air pollution in three Latin American cities: Santiago, Sao Paulo, and Mexico City. Environ Res 100:431-440

Beltrán E, Rojas M (1996) Diversified funding methods in Mexican archeology. Ann Tour Res 23(2):463-478

Birol E, Villalba ER, Smale M (2009) Farmer preferences for milpa diversity and genetically modified maize in Mexico: a latent class approach. Env Dev Econ 14(4):521-540

Brander LM, Koetse MJ (2011) The value of urban open space: meta-analyses of contingent valuation and hedonic pricing results. J Env Manag 92(10):2763-2773

Calderón-Garcidueñas L, Mora-Tiscareño A, Ontiveros E, Gómez-Garza G, Barragán-Mejía G, Broadway J, Engle RW (2008) Air pollution, cognitive deficits and brain abnormalities: a pilot study with children and dogs. Brain Cogn 68(2):117-127

Carlsson F, Johansson-Stenman O (2000) Willingness to pay for improved air quality in Sweden. Appl Econ 32:661-669

Carson RT (2012) Contingent valuation: a practical alternative when prices aren't available. J Econ Perspect 26(4):27-42

Carson RT, Flores NE, Meade NF (2001) Contingent valuation: controversies and evidence. Env Resour Econ 19:173-210

Centro de Estudios de las Finanzas Públicas (CEFP) (2009) "Perfil socioeconómico del Distrito Federal," Cámara de Diputados, CEFP/037/2009. http://www.cefp.gob.mx/intr/edocumentos/pdf/cefp/2009/ cefp0372009.pdf. Accessed 8 Nov 2016

Cesar H, Borja-Aburto VH, Dorland K, Muñoz-Cruz R, Brander L, Cropper M, Gonzalez-Martinez AC, Olaiz-Fernandez G, Vergara W (2002) "Improving air quality in metropolitan Mexico City: an economic valuation," World Bank, The Mexico Air Quality Management Team, Policy Research Working Papers. http://elibrary.worldbank.org/doi/abs/10.1596/1813-9450-2785. Accessed 8 Nov 2016

Chen WY, Hua J (2015) Citizens' distrust of government and their protest responses in a contingent valuation study of urban heritage trees in Guangzhou, China. J Env Manag 155:40-48

Clear Air Institute (CAI) (2013) "La calidad del aire en América Latina: Una visión panorámica," Washington D.C., USA. http://www.cleanairinstitute.org/calidaddelaireamericalatina/cai-reportspanish.pdf. Accessed 8 Nov 2016

Cooper JC, Hanemman M, Signorello G (2002) One-and-one-half-bound dichotomous choice contingent valuation. Rev Econ Stat 84(4):472-750

Davis LW (2008) The effect of driving restrictions on air quality in Mexico City. J Polit Econ 116(1):38-81 
Escamilla-Nuñez MC, Barraza-Villarreal A, Hernandez-Cadena L, Moreno-Macias H, Ramirez-Aguilar M, Sienra-Monge JJ, Cortez-Lugo M, Texcalac JL, del Rio-Navarro B, Romieu I (2008) Trafficrelated air pollution and respiratory symptoms among asthmatic children, resident in Mexico City: the EVA cohort study. Respir Res 9(1):74-85

Gallego F, Montero JP, Salas C (2013a) The effect of transport policies on car use: a bundling model with applications. Energy Econ 40(S1):85-97

Gallego F, Montero JP, Salas C (2013b) The effect of transport policies on car use: evidence from Latin American cities. J Public Econ 107:47-62

García-Robles C (2010) "Escenarios de consumo de energía y emisiones de gases de efecto invernadero del transporte de pasajeros de la zona metropolitana de la ciudad de México," UNAM, master thesis. http://www.ptolomeo.unam.mx:8080/xmlui/bitstream/handle/132.248.52.100/3995/garciarobles.pdf? sequence $=1$. Accessed 8 Nov 2016

Gonzalez F, Leipnik M, Mazumder D (2013) How much are urban residents in Mexico willing to pay for cleaner air? Env Dev Econ 18(3):354-379

Haab TC, McConnell KE (2002) Valuing environmental and natural resources: the econometrics of nonmarket valuation. Edward Elgar Publishing, Cheltenham, UK

Hammitt JK, Ibarrarán ME (2006) The economic value of fatal and non-fatal occupational risks in Mexico City using actuarial- and perceived-risk estimates. Health Econ 15:1329-1335

Hanemann M, Loomis J, Kanninen B (1991) Statistical efficiency of double-bounded dichotomous choice contingent valuation. Am J Agric Econ 73(4):1255-1263

Hanna R, Oliva P (2015) The effect of pollution on labor supply: evidence from a natural experiment in Mexico City. J Public Econ 122:68-79

Heredia-Pi IB, Servan-Mori E, Reynales-Shigematsu LM, Bautista-Arredondo S (2012) The maximum willingness to pay for smoking cessation method among adult smokers in Mexico. Value Health 15(5):750-758

Husted BW, Russo MV, Basurto-Meza CE, Tilleman SG (2014) An exploratory study of environmental attitudes and the willingness to pay for environmental certification in Mexico. J Bus Res 67(5):891-899

Instituto Nacional de Estadística y Geografía (INEGI) (2010) Panorama sociodemográfico del Distrito Federal. http://documents.mx/documents/delegaciones-panorama-df.html. Accessed 8 Nov 2016

Instituto Nacional de Estadística y Geografía (INEGI) (2016) Vehículos de motor registrados en circulación. http://www.inegi.org.mx/est/lista_cubos/consulta.aspx?p=adm\&c=8. Accessed 8 Nov 2016

Kling CL, Phaneuf DJ, Zhao J (2012) From Exxon to BO: has some number become better than no number. J Econ Perspect 26(4):3-26

Krinsky I, Robb AL (1986) On approximating the statistical properties of elasticities. Rev Econ Stat 68(4):715-719

Margulis S (1996) Back-of-the-envelope estimates of environmental damage costs in Mexico. In: May $\mathrm{PH}$, da Motta RS (eds) Pricing the planet: economic analysis for sustainable development. Columbia University Press, New York

Martínez-Cruz AL, Sainz-Santamaría J (2015) Recreational Value of Two Peri-urban forests in Mexico City, working paper. https://www.researchgate.net/profile/Adan_Martinez-Cruz/publication/ 282132523_Recreational_value_of_two_peri-urban_forests_in_Mexico_City/links/560415ce08aeb 5718feedc41.pdf. Accessed 8 Nov 2016

Martínez-Espiñeira R, Lyssenko N (2011) Correcting for the endogeneity of pro-environmental behavioral choices in contingent valuation. Ecol Econ 70:1435-1439

McKinley G, Zuk M, Höjer M, Avalos M, González I, Iniestra R, Laguna I, Martínez MA, Osnaya P, Reynales LM, Valdés R, Martínez J (2005) Quantification of local and global benefits from air pollution control in Mexico City. Env Sci Technol 39(7):1954-1961

Molina M, Molina L (eds) (2002) Air quality in the Mexico megacity: an integrated assessment, vol 15. Kluwer Academic Publishers, New York

Nyborg K (2000) Homo economicus and homo politicus: interpretation and aggregation of environmental values. J Econ Behav Organ 42:305-322

Oliva P (2012) Environmental regulations and corruption: automobile emissions in Mexico City, University of California at Santa Barbara Working Paper. http://www.econ.ucsb.edu/ oliva/Docs/ Smog_Checks_Jan2012.pdf. Accessed 8 Nov 2016

Pérez-Verdin G, Navar-Chaidez J, Kim Y, Silva-Flores R (2011) Valuing watershed services in mexico's temperate forests. Modern Econ 2(05):769-779 
Poe GL, Severance-Lossin EK, Welsh MP (1994) Measuring the difference (X-Y) of simulated distributions: a convolution approach. Am J Agric Econ 76:904-915

Poe GL, Welsh MP, Champ PA (1997) Measuring the difference in mean willingness to pay when dichotomous choice contingent valuation responses are not independent. Land Econ 73:255-267

Proaire (2001) "Programa para mejorar la calidad del aire de la ZMVM 2002-2010". http://www.aire. cdmx.gob.mx/descargas/publicaciones/gestion-ambiental-aire-memoria-documental-2001-2006/ descargas/proaire_2002-2010.pdf. Accessed 8 Nov 2016

Rivera-Planter M, Muñoz-Piña C (2005) Fees for Reefs: economic Instruments to Protect Mexico's Marine Natural Areas. Curr Issues Tour 8(2-3):195-213

Rodríguez-Sánchez JI (2014) Do Mexicans care about air pollution? Lat Am Econ Rev 1:1-24

Romieu I, Barraza-Villarreal A, Escamilla-Nuñez C, Almstrand AC, Diaz-Sanchez D, Sly PD, Olin AC (2008) Exhaled breath malondialdehyde as a marker of effect of exposure to air pollution in children with asthma. J Allergy Clin Immunol 121(4):903-909

Sánchez-Brito I, Almendarez-Hernández MA, Morales-Zárate MV, Salinas Zavala CA (2013) Valor de existencia del servicio ecosistémico hidrológico en la Reserva de la Biosfera Sierra La Laguna, Baja California Sur, México. Frontera norte 25(50):97-129

Scarpa R, Drucker AG, Anderson S, Ferraes-Ehuan N, Gomez V, Risopatron CR, Rubio-Leonel O (2003) Valuing genetic resources in peasant economies: the case of 'hairless' creole pigs in Yucatan. Ecol Econ 45(3):427-443

Secretaria del Medio Ambiente del Gobierno del Distrito Federal (SMAGDF) (2009) "Calidad del aire en la Ciudad de México, Informe 2009". http://www.aire.df.gob.mx/descargas/publicaciones/ flippingbook/informe_anual_calidad_aire_2009/. Accessed 8 Nov 2016

Soto-Montes de Oca G, Bateman IJ (2006) Scope sensitivity in households' willingness to pay for maintained and improve water supplies in a developing world urban area: investigating the influence of baseline supply quality and income distribution upon stated preferences in Mexico City. Water Resour Res 42:W07421. doi:10.1029/2005WR003981

Spash CL (2006) Non-economic motivation for contingent values: rights and attitudinal beliefs in the willingness to pay for environmental improvements. Land Economics 82(4):602-622

Spash CL, Urama K, Burton R, Kenyon W, Shannon P, Hill G (2009) Motives behind willingness to pay for improving biodiversity in a water ecosystem: economics, ethics and social psychology. Ecol Econ 68:955-964

Strazzera E, Scarpa R, Calia P, Garrod GD, Willis KG (2003) Modelling zero values and protest responses in contingent valuation surveys. Appl Econ 35(2):133-138

Tonsor GT, Schroeder TC, Pennings JME, Mintert J (2009) Consumer valuations of beef steak food safety enhancement in Canada, Japan, Mexico, and the United States. Can J Agric Econ 57(3):395-416

Vargas-Bustamante A, Ojeda G, Castañeda X (2008) Willingness to pay for cross-border health insurance between the United States and Mexico. Health Aff 27(1):169-178

Vásquez WF, Mozumder P, Hernández-Arce J, Berrens RP (2009) Willingness to pay for safe drinking water: evidence from Parral, Mexico. J Env Manage 90:3391-3400

Wang Y, Zhang YS (2009) Air quality assessment by contingent valuation in Jínan, China. J Env Manag 90:1022-1029

Whittington D (2002) Improving the performance of contingent valuation studies in developing countries. Env Resour Econ 22:323-367 